Received 00th January 20xx, Accepted 00th January 20xx DOI: $10.1039 / x 0 x \times 00000 x$

\title{
Incorporating rare-earth cations with moderate electropositivity into iodates for the optimized second-order nonlinear optical performance
}

\author{
Lin Lin, ${ }^{a}$ Chao Wu, ${ }^{a}$ Longhua Li, ${ }^{a}$ Zhipeng Huang, ${ }^{a}$ Mark G. Humphrey ${ }^{b}$ and Chi Zhang*a
}

\begin{abstract}
Infrared (IR) nonlinear optical (NLO) materials have attracted tremendous interest for civil and military applications, but it remains a great contemporary challenge to develop high-efficiency NLO crystals that possess sufficiently high secondharmonic generation (SHG) efficiencies coupled to wide transparency ranges and high laser damage thresholds. A series of new hydrous rare-earth iodates $\mathrm{RE}\left(\mathrm{IO}_{3}\right)_{3} \cdot\left(\mathrm{H}_{2} \mathrm{O}\right)(\mathrm{RE}=\mathrm{Y} \mathbf{1}, \mathrm{Eu} \mathbf{2})$ and $\mathrm{La}_{2}\left(\mathrm{IO}_{3}\right)_{6}\left(\mathrm{H}_{2} \mathrm{O}\right)(\mathbf{3})$ have been synthesized through facile hydrothermal methods. $\mathbf{1}$ and $\mathbf{2}$ are isostructural, crystallizing in the polar space group $P 2_{1}$, while $\mathbf{3}$ crystallizes in the polar space group Pc. 1-3 feature three-dimensional (3D) frameworks composed of alternately connected corner-shared distorted [REO $\mathrm{x}$ ] polyhedra ( $\mathrm{RE}=\mathrm{Y}, \mathrm{Eu}$, and $\mathrm{La} ; \mathrm{x}=8,9)$ and $\left[\mathrm{IO}_{3}\right]^{-}$groups. Optical studies showed that $\mathbf{1 - 3}$ exhibit good NLO properties, including strong SHG intensities $\left(3.0 \times(\mathbf{1}), 4.5 \times(\mathbf{2})\right.$, and $\left.1.5 \times \mathrm{KH}_{2} \mathrm{PO}_{4}(\mathbf{3})\right)$, large band gaps (4.12 (1), $4.36(\mathbf{2})$, and $4.24 \mathrm{eV}$ (3), with 2 possessing the largest band gap among the known SHG-active rare-earth-based iodates, high laser damage thresholds (LDT) $\left(53 \times(\mathbf{1}), 43 \times(2)\right.$, and $\left.44 \times \mathrm{AgGaS}_{2}(\mathbf{3})\right)$, and wide transparency ranges (ca. 3.0-11.3 $\mu \mathrm{m}$ ) in the mid-IR region covering two critical IR transparency windows; $\mathbf{1 - 3}$ are therefore potential candidate NLO materials. Density functional theory calculations on 1-3 confirm that their strong SHG responses and large band gaps are mainly derived from the synergistic effect of $\left[\mathrm{IO}_{3}\right]^{-}$groups and rare-earth oxide polyhedra [REOx] in their 3D frameworks. We conclude that the introduction of rare-earth cations with moderate electropositivity into iodates may optimize the balance between SHG efficiency and optical band gaps, the key requirement for high-performance NLO materials for practical applications.
\end{abstract}

\section{Introduction}

Second-order nonlinear optical (NLO)-active materials that can generate coherent and tunable light in the infrared (IR) region are crucial for various chemical, medical, industrial, and military applications. ${ }^{1-3}$ Many NLO crystal materials (e.g. the well-known 6- $\mathrm{BaB}_{2} \mathrm{O}_{4}$ (BBO), ${ }^{4} \mathrm{LiB}_{3} \mathrm{O}_{5}$ (LBO), ${ }^{5} \mathrm{CsB}_{3} \mathrm{O}_{5}$ (CBO), ${ }^{6} \mathrm{Sr}_{2} \mathrm{Be}_{2} \mathrm{~B}_{2} \mathrm{O}_{7}$ $(\mathrm{SBBO}),{ }^{7} \mathrm{KTiOPO}_{4}(\mathrm{KTP}),{ }^{8} \mathrm{KH}_{2} \mathrm{PO}_{4}(\mathrm{KDP}),{ }^{4}$ etc.) are available and are widely used in the ultraviolet and visible regions. However, the commercialized NLO materials for use in the IR region (e.g. $\mathrm{AgGaS}_{2},{ }^{9} \mathrm{AgGaSe}_{2},{ }^{10}$ and $\mathrm{ZnGeP}_{2}{ }^{11}$ ) suffer from the inherent limitations of low laser damage thresholds (LDTs), phase mismatching at the desired operating wavelengths, and deleterious two-photon absorption. ${ }^{12,13} \mathrm{~A}$ high-performance IR NLO crystalline material with an optimal balance of the competing optical performance characteristics is yet to be discovered, and consequently is in high demand.

The prerequisite for a second-order NLO crystalline material is crystallographic non-centrosymmetry (NCS), and the

\footnotetext{
a. China-Australia Joint Research Center for Functional Molecular Materials, School of Chemical Science and Engineering, Tongji University, Shanghai 200092, P. R. China.E-mail: chizhang@tongji.edu.cn

b. Research School of Chemistry, Australian National University, Canberra, ACT 2601, Australia

+ Electronic Supplementary Information (ESI) available. CCDC 1943484-1943486. See DOI: $10.1039 / x 0 x x 00000 x$
}

presence of asymmetric structural units may promote the formation of a macroscopic NCS structure. ${ }^{14}$ As a result, one effective strategy for developing new NLO materials is to introduce asymmetric structural units such as planar triangular anionic groups (e.g. $\pi$-conjugated $\left.\left[\mathrm{BO}_{3}\right]^{3-},\left[\mathrm{CO}_{3}\right]^{2-},\left[\mathrm{NO}_{3}\right]^{-}\right),{ }^{15-17}$ cations that contain stereochemically-active lone-pairs (e.g., $\left.\mathrm{Se}^{4+}, \mathrm{Te}^{4+}, \mathrm{I}^{5+}\right),{ }^{18-20}$ and $\mathrm{d}^{0}$ transition-metal cations (e.g., $\mathrm{Ti}^{4+}, \mathrm{V}^{5+}$, $\left.\mathrm{Mo}^{6+}, \mathrm{W}^{6+}\right){ }^{21-23}$ Of these possibilities, the $\left[\mathrm{IO}_{3}\right]^{-}$anion in metal iodates is such a NLO-active group that can not only favor an NCS structure, but also contribute to large second-harmonic generation (SHG) efficiencies. Metal iodates meet almost all the prerequisites for possible IR NLO materials, including large SHG effects, a wide optical transparency range from the UV to the IR region, relatively large optical band gaps that correspond to high LDTs, good thermal stabilities, easy-to-grow bulk crystals, and moderate rigidity. ${ }^{18,24}$ Consequently, the $\left[\mathrm{IO}_{3}\right]^{-}$group has been proposed as a building unit in the design of NLO materials due to the advantages above and, indeed, significant advances have been achieved in the development of iodate NLO materials (e.g. the well-known $\alpha$ - $\mathrm{LilO}_{3},{ }^{25} \mathrm{Nal}_{3} \mathrm{O}_{9},{ }^{26} \mathrm{AgI}_{3} \mathrm{O}_{9},{ }^{27} \mathrm{BiO}\left(\mathrm{IO}_{3}\right)_{3},{ }^{28}$ and $\left.\mathrm{AlO}_{3}(\mathrm{~A}=\mathrm{Rb}, \mathrm{Cs})^{29,30}\right)$.

The band gaps and LDTs of the existing iodate NLO materials need further improvement for practical applications. The introduction of highly electronegative fluorine or strongly electropositive metal cations into metal iodates can improve the band gap but at the expense of a reduction in SHG efficiency, ${ }^{29,30}$ consistent with the known negative correlation 
between SHG efficiency and ionicity; ${ }^{31,32}$ the strong electropositivity of alkali/alkaline-earth metal cations and electronegativity of halide anions strengthen the ionic nature of the target compound, leading to a weak SHG response. To address this shortcoming, we considered the introduction of rare-earth cations with moderate electropositivity into iodate structures, because rare-earth iodates (except cerium iodates) not only possess superior band gaps $(>4.0 \mathrm{eV}), 33,34$ but they also possess key spectral characteristics ${ }^{35-37}$ that are exploited in fluorescence and laser applications.

To the best of our knowledge, few NLO-efficient rare-earth iodates are existent, $33,35,38,39$ a result of the drawbacks exhibited by the existing examples. ${ }^{40-43} \mathrm{UO}_{2}\left(\mathrm{IO}_{3}\right)_{2} \cdot \mathrm{H}_{2} \mathrm{O}$ and $\mathrm{Th}_{2}\left(\mathrm{IO}_{3}\right)_{8}\left(\mathrm{H}_{2} \mathrm{O}\right)$ possess relatively weak SHG efficiencies coupled to harmful radioactivity, ${ }^{40}$ cerium iodates exhibit large SHG effects, but have small band gaps and thereby low LDTs, ${ }^{40-42}$ and the relatively low thermal stability of $\mathrm{La}\left(\mathrm{IO}_{3}\right)_{3}$ limits its prospects in practical applications. ${ }^{43}$ As a consequence, the development of new iodate NLO materials optimizing these performance criteria remains a major challenge.

With the above considerations in mind, we herein introduce several rare-earth cations with moderate electropositivity into iodate system to construct new NCS materials. Three new acentric hydrous trivalent rare-earth iodates $\mathrm{Y}\left(\mathrm{IO}_{3}\right)_{3} \cdot \mathrm{H}_{2} \mathrm{O}(\mathbf{1})$, $\mathrm{Eu}\left(\mathrm{IO}_{3}\right)_{3} \cdot \mathrm{H}_{2} \mathrm{O}$ (2) and $\mathrm{La}_{2}\left(\mathrm{IO}_{3}\right)_{6}\left(\mathrm{H}_{2} \mathrm{O}\right)$ (3) have been obtained through facile hydrothermal methods. Optical property studies reveal that they possess relatively large band gaps (1: 4.12, 2 : 4.36, 3: $4.24 \mathrm{eV})$, wide transparency windows $(1: 3.0-11.3,2$ : 3.2-10.4, 3: 3.2-11.0 $\mu \mathrm{m})$, large SHG responses (1: $3.0 \times, 2: 4.5$ $\times, 3: 1.5 \times \mathrm{KDP})$ and high LDTs $\left(1: 53 \times, 2: 43 \times, 3: 44 \times \mathrm{AgGaS}_{2}\right)$, suggesting that these rare-earth iodates are potential NLO crystalline materials in the IR region. Density functional theory calculations have been performed on these iodates, revealing that the strong SHG responses and large band gaps mainly derive from a synergistic effect of the $\left[\mathrm{IO}_{3}\right]^{-}$groups and rareearth oxide polyhedra. This study demonstrates that the introduction of rare-earth cations with moderate electropositivity into anionic systems may be a useful strategy for the construction of high-performance second-order NLO crystalline materials.

\section{Experimental section}

\section{Reagents}

Starting materials $\mathrm{Y}_{2} \mathrm{O}_{3}$ (99.9\%, Adamas-Beta), $\mathrm{Eu}_{2} \mathrm{O}_{3}$ (99.99\%, Adamas-Beta), $\mathrm{La}\left(\mathrm{NO}_{3}\right)_{3} \cdot 6 \mathrm{H}_{2} \mathrm{O}\left(99 \%\right.$, Adamas-Beta), $\mathrm{I}_{2} \mathrm{O}_{5}(99 \%$, Adamas-Beta), $\mathrm{HIO}_{3}$ (99\%, Adamas-Beta), $\mathrm{Cs}_{2} \mathrm{CO}_{3} \quad(99 \%$, Adamas-Beta) and tetrafluoroboric acid (40 wt\% solution in water, AR, Greagent) were obtained from commercial sources and were used as received.

\section{Syntheses}

Synthesis of 1. A mixture of $\mathrm{Y}_{2} \mathrm{O}_{3}(0.113 \mathrm{~g}, 0.50 \mathrm{mmol}), \mathrm{I}_{2} \mathrm{O}_{5}$ $(0.501 \mathrm{~g}, 1.50 \mathrm{mmol}), \mathrm{Cs}_{2} \mathrm{CO}_{3}(0.163 \mathrm{~g}, 0.50 \mathrm{mmol})$, and deionized water $(3 \mathrm{~mL})$ was tightly sealed in a $20 \mathrm{~mL}$ autoclave equipped with a Teflon liner. The autoclave was heated at 230
${ }^{\circ} \mathrm{C}$ for $72 \mathrm{~h}$, and then cooled slowly to room temperature at a rate of $4{ }^{\circ} \mathrm{C} / \mathrm{h}$. The product was collected by vacuum filtration, washed with deionized water, and then dried in the air. Colorless sheet crystals of 1 were isolated using a microscope (0.266 g, 42\% based on Y).

Synthesis of 2. A small amount of tetrafluoroboric acid and a relatively low temperature were employed to synthesize the rare-earth europium iodate $\mathbf{2}$. The detailed synthetic route, modified from the synthesis of 1 , is as follows: $\mathrm{Eu}_{2} \mathrm{O}_{3}(0.176 \mathrm{~g}$, $0.50 \mathrm{mmol}), \mathrm{I}_{2} \mathrm{O}_{5}(0.501 \mathrm{~g}, 1.50 \mathrm{mmol})$, tetrafluoroboric acid $(200 \mu \mathrm{L})$ and deionized water $(2 \mathrm{~mL})$ were sealed in the same autoclave as above, and the mixture was heated at $160{ }^{\circ} \mathrm{C}$ for $72 \mathrm{~h}$ with the other steps the same as described above, affording colorless needle crystals of $2(0.574 \mathrm{~g}, 83 \%$ based on $\mathrm{Eu})$.

Synthesis of 3. A similar synthetic route, modified from the synthesis of 2, was employed as follows: A mixture of $\mathrm{La}\left(\mathrm{NO}_{3}\right)_{3} \cdot 6 \mathrm{H}_{2} \mathrm{O}(0.346 \mathrm{~g}, 0.80 \mathrm{mmol}), \mathrm{HIO}_{3}(0.528 \mathrm{~g}, 3.00 \mathrm{mmol})$, tetrafluoroboric acid $(80 \mu \mathrm{L})$ and deionized water $(2 \mathrm{~mL})$ was sealed in the same autoclave. The autoclave was heated at 180 ${ }^{\circ} \mathrm{C}$ for $72 \mathrm{~h}$ and then cooled to room temperature at a rate of 4 ${ }^{\circ} \mathrm{C} / \mathrm{h}$. Colorless block crystals of $\mathbf{3}$ were obtained $(0.419 \mathrm{~g}, 78 \%$ based on La).

\section{Structure determinations}

Single-crystal X-ray diffraction data sets for 1-3 were collected on a Bruker D8 VENTURE CMOS X-ray diffractometer equipped with a CCD detector using graphite-monochromated Mo $\mathrm{K} \alpha$ radiation ( $\lambda=0.71073 \AA$ ) at $293 \mathrm{~K}$. The data were obtained with scan widths of $1.00^{\circ}$ and an exposure time of 3 seconds per frame. The software APEX II was used for data collection and reduction as well as multi-scan absorption correction. The crystal structures were solved by direct methods and refined on $F^{2}$ by full-matrix least-squares using the SHELXTL-97 program package. ${ }^{44,45}$ All of the non-hydrogen atoms were refined with anisotropic thermal parameters. $\mathrm{O}(10)$ in $\mathbf{1}$ and $\mathbf{2}$ are assigned as oxygen atoms in $\mathrm{H}_{2} \mathrm{O}$ molecules, consistent with charge balance requirements and bond valence sum (BVS) calculations. ${ }^{46}$ Following geometry optimizations, the bond valences of $\mathrm{O}(10)$ are 2.36 and 2.31 for 1 and 2, respectively. $\mathrm{O}(19)$ in $\mathbf{3}$ is also assigned as the oxygen atom of a $\mathrm{H}_{2} \mathrm{O}$ molecule, its bond valence being 2.59 after geometry optimization. All the structural data sets were examined for possible missing symmetry by using the program PLATON, no higher symmetry being found. ${ }^{47}$ Detailed crystallographic data and refinement parameters are listed in Table 1, and isotropic displacement parameters and atomic bond valence calculation results of the three compounds are listed in Table S1.

\section{Powder X-ray diffraction (PXRD)}

Powder X-ray diffraction measurements on finely-ground polycrystalline samples of 1-3 were performed using a Bruker D8 ADVANCE diffractometer equipped with $\mathrm{Cu} \mathrm{K} \alpha$ radiation. Data were collected in the $2 \vartheta$ range $5^{\circ}-70^{\circ}$ with a step size of $0.02^{\circ}$ and a scan rate of 1 second per step.

Infrared spectroscopy measurements 
Table.1 Crystallographic data and structure refinement parameters for 1-3.

\begin{tabular}{|c|c|c|c|}
\hline Formula & $\left.\mathrm{Y}\left(\mathrm{IO}_{3}\right)_{3} \cdot \mathrm{H}_{2} \mathrm{O}\right)(\mathbf{1})$ & $\left.\mathrm{Eu}\left(\mathrm{IO}_{3}\right)_{3} \cdot \mathrm{H}_{2} \mathrm{O}\right)(2)$ & $\mathrm{La}_{2}\left(\mathrm{IO}_{3}\right)_{6}\left(\mathrm{H}_{2} \mathrm{O}\right)(3)$ \\
\hline Formula weight & 631.63 & 694.68 & 1345.24 \\
\hline Temperature & $293(2) K$ & $293(2) K$ & $293(2) K$ \\
\hline Crystal system & Monoclinic & Monoclinic & Monoclinic \\
\hline Space group & $P 2_{1}$ & $P 2_{1}$ & $P c$ \\
\hline$a(\AA)$ & $7.2427(3)$ & $7.3037(8)$ & $7.3013(2)$ \\
\hline$b(\AA)$ & $6.5833(3)$ & $6.6412(7)$ & $11.1669(3)$ \\
\hline$c(\AA ̊)$ & $9.7970(4)$ & $9.8878(11)$ & $12.8828(3)$ \\
\hline$B\left(^{\circ}\right)$ & $109.8680(10)$ & $109.760(5)$ & $122.6770(10)$ \\
\hline$V\left(\AA^{3}\right)$ & $439.32(3)$ & $451.37(9)$ & $884.13(4)$ \\
\hline Z & 2 & 2 & 2 \\
\hline$\rho_{\text {calc }} / \mathrm{g} \cdot \mathrm{cm}^{-3}$ & 4.767 & 5.111 & 5.053 \\
\hline$\mu / \mathrm{mm}^{-1}$ & 17.216 & 17.244 & 15.337 \\
\hline$F(000)$ & 560 & 608 & 1172 \\
\hline$\vartheta($ deg) & $2.99-27.16$ & $2.96-26.47$ & $3.31-27.14$ \\
\hline$R_{\text {int }}$ & 0.0338 & 0.0254 & 0.0475 \\
\hline Reflections collected / unique & $7742 / 1911$ & $1603 / 1408$ & $16309 / 3572$ \\
\hline Absolute structure parameter & -0.047 & 0 & -0.03 \\
\hline GOF on $F^{2}$ & 1.189 & 1.020 & 0.989 \\
\hline$R_{1} / \mathrm{w} R_{2}[\mathrm{I}>2 \sigma(\mathrm{I})]^{\mathrm{a}}$ & $0.0213 / 0.0524$ & $0.0302 / 0.0760$ & $0.0232 / 0.0445$ \\
\hline$R_{1} / w R_{2}$ (all data) & $0.0216 / 0.0526$ & $0.0323 / 0.0772$ & $0.0255 / 0.0451$ \\
\hline Largest diff. peak and hole $\left(e \AA^{-3}\right)$ & 0.919 and -2.559 & 2.563 and -1.485 & 0.948 and -1.245 \\
\hline
\end{tabular}

Fourier transform infrared (FTIR) spectra of 1-3 were collected in reflectance mode using a Thermo Scientific Nicolet iS10 FT-IR spectrometer in the range $4000-400 \mathrm{~cm}^{-1}$ with a spectral resolution of $4 \mathrm{~cm}^{-1}$. Mixtures of each of 1-3 and dried $\mathrm{KBr}$ in a mass ratio of 1:50 were ground thoroughly and pressed into disks for testing.

\section{UV-Vis-NIR diffuse reflectance spectrum measurements}

UV-Vis-NIR diffuse reflectance spectra of 1-3 were obtained on an Agilent Cary 5000 UV-Vis-NIR spectrophotometer in the range $200-2500 \mathrm{~nm}$ at room temperature and using a $\mathrm{BaSO}_{4}$ plate as the standard (100\% reflectance). The Kubelka-Munk function, $\alpha / S=(1-R)^{2} / 2 R$, where $\alpha$ is the absorption coefficient, $S$ is the scattering coefficient that is practically wavelength-independent when the particle sizes are larger than $5 \mu \mathrm{m}$, and $R$ is the reflectance, was employed to calculate the absorption spectra from the reflectance spectra. ${ }^{48}$

\section{Thermogravimetric analyses}

Thermogravimetric analysis (TGA) experiments were performed on a Netzsch STA 409PC instrument. Finely ground polycrystalline samples of 1-3 were added to an $\mathrm{Al}_{2} \mathrm{O}_{3}$ crucible and heated up to $900{ }^{\circ} \mathrm{C}$ from room temperature at a rate of 15

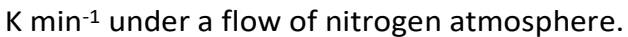

\section{Second-harmonic generation measurements}

Measurements of the powder second-harmonic generation were carried out on polycrystalline samples of 1-3 using the Kurtz-Perry method. ${ }^{49}$ A Q-switched Nd:YAG laser at $1064 \mathrm{~nm}$ was employed. The polycrystalline samples of 1-3 were ground and sieved into several different particle size ranges $(<26,26-$
50, 50-74, 74-105, 105-150, 150-200 $\mu \mathrm{m}$ ), and pressed into disks with diameters of $6 \mathrm{~mm}$ that were placed between glass microscope slides and secured with tape in a $1 \mathrm{~mm}$ thick aluminum holder. Crystalline KDP (serving as the reference) was also sieved into the same particle size ranges and tested under the same conditions. The SHG efficiency was evaluated by comparing oscilloscope traces of the SHG signal of KDP and 1-3 at the particle size range of $105-150 \mu \mathrm{m}$.

\section{Laser damage threshold measurements}

The LDTs of 1-3 and reference AgGaS 2 were measured using a single-pulse method ${ }^{50}$ with a $1064 \mathrm{~nm}$ Q-switched Nd:YAG solidstate laser. Crystals of 1-3 and $\mathrm{AgGaS}_{2}$ were ground into the size range 105-150 $\mu \mathrm{m}$ with the same processing. The crystalline samples were then pressed between two glass slides and examined under a pulsed laser beam (1064 nm, $10 \mathrm{~ns})$. During the measurements, the pulse energy was slowly raised from 1 $\mathrm{mJ}$ until obvious damage spots on the samples were observed under a magnifier.

\section{Theoretical calculations}

The electronic structures and energies were calculated using density functional theory (DFT) and the VASP code. ${ }^{51}$ The generalized gradient approximation (GGA) scheme of PerdewBurke-Ernzerhof (PBE) ${ }^{52}$ was utilized to calculate the exchange correlation interaction. A plane-wave basis set with a frozencore projector-augmented wave (PAW) ${ }^{53,54}$ potential and a plane-wave cut-off energy of $520 \mathrm{eV}$ was used for 1-3. A grid of $5 \times 5 \times 4,5 \times 5 \times 4,6 \times 6 \times 4$ Monkhorst-Pack $k$-points was used for the self-consistent-field convergence of the total electronic energy of $\mathbf{1}, \mathbf{2}$, and $\mathbf{3}$, respectively. A total of $340 \mathrm{k}$ points in the 
full Brillouin zone and 100 unoccupied bands were applied to generate the momentum matrix elements, which were used in the SHG calculations. ${ }^{55}$ The second-order susceptibility $\chi^{(2)}(-2 \omega$, $\omega, \omega)$ was obtained from the electronic band structures according to literature equations. ${ }^{56}$

\section{Results and discussion}

\section{Syntheses}

All three crystalline samples 1-3 were synthesized under facile hydrothermal reaction conditions according to the reaction equations (1)-(3):

$\mathrm{Y}_{2} \mathrm{O}_{3}+4 \mathrm{I}_{2} \mathrm{O}_{5}+2 \mathrm{CsCO}_{3}+2 \mathrm{H}_{2} \mathrm{O} \rightarrow 2 \mathrm{Y}\left(\mathrm{IO}_{3}\right)_{3}\left(\mathrm{H}_{2} \mathrm{O}\right)+2 \mathrm{CsIO}_{3}+2 \mathrm{CO}_{2}$ $\uparrow(1)$

$\mathrm{Eu}_{2} \mathrm{O}_{3}+3 \mathrm{I}_{2} \mathrm{O}_{5}+\mathrm{HBF}_{4}+3 \mathrm{H}_{2} \mathrm{O} \rightarrow 2 \mathrm{Eu}\left(\mathrm{IO}_{3}\right)_{3}\left(\mathrm{H}_{2} \mathrm{O}\right)+\mathrm{HBF}_{3} \mathrm{OH}+\mathrm{HF}$ (2)

$2 \mathrm{La}\left(\mathrm{NO}_{3}\right)_{3} \cdot 6 \mathrm{H}_{2} \mathrm{O}+6 \mathrm{HIO}_{3}+\mathrm{HBF}_{4} \rightarrow \mathrm{La}_{2}\left(\mathrm{IO}_{3}\right)_{6}\left(\mathrm{H}_{2} \mathrm{O}\right)+\mathrm{HBF}_{3} \mathrm{OH}+\mathrm{HF}$ $+6 \mathrm{HNO}_{3}+10 \mathrm{H}_{2} \mathrm{O}(3)$

As shown in equation (1), a small amount of $\mathrm{Cs}_{2} \mathrm{CO}_{3}$ is necessary for the construction of 1 ; in the absence of $\mathrm{Cs}_{2} \mathrm{CO}_{3}$, the starting material $\mathrm{Y}_{2} \mathrm{O}_{3}$ is almost all converted to $\mathrm{Y}\left(\mathrm{IO}_{3}\right)_{3},{ }^{57}$ rather than the hydrous iodate $\mathrm{Y}\left(\mathrm{IO}_{3}\right)_{3}\left(\mathrm{H}_{2} \mathrm{O}\right) \mathbf{1}$. We assume that the $\mathrm{Cs}_{2} \mathrm{CO}_{3}$ buffers the $\mathrm{pH}$ of the reaction solution to the ideal range; the initial and final $\mathrm{pH}$ values for the syntheses of 1 were 1.5 and 6.0 with $\mathrm{Cs}_{2} \mathrm{CO}_{3}$, in contrast to 1.0 and 5.0 without $\mathrm{Cs}_{2} \mathrm{CO}_{3}$. For the synthesis of $\mathbf{2}$ (reaction (2)), the reaction reagents and stoichiometry are critical. For example, a lower ratio (1:4) of $\mathrm{Eu}_{2} \mathrm{O}_{3} / \mathrm{I}_{2} \mathrm{O}_{5}$ leads to the formation of $\mathrm{Eu}\left(\mathrm{IO}_{3}\right)_{3}\left(\mathrm{H}_{2} \mathrm{O}\right) \cdot \mathrm{H}_{2} \mathrm{O}^{58}$ as the main product, rather than 2 . Attempts were made to use $\mathrm{Eu}\left(\mathrm{NO}_{3}\right)_{3} \cdot 6 \mathrm{H}_{2} \mathrm{O}$ and $\mathrm{HIO}_{3}$ as the $\mathrm{Eu}$ and I source, but these failed to afford $\mathbf{2}$. It is noteworthy that $\mathbf{2}$ could only be obtained under acid conditions and that a small amount of tetrafluoroboric acid improves the crystal quality of 2; a lack of acid or the use of excess tetrafluoroboric acid results in a microcrystalline phase only. $\mathrm{Gd}\left(\mathrm{IO}_{3}\right)_{3}\left(\mathrm{H}_{2} \mathrm{O}\right)$, which is isostructural with $\mathbf{1}$ and $\mathbf{2}$, was synthesized via a hydrothermal reaction of $\mathrm{Gd}_{2} \mathrm{O}_{3}, \mathrm{CuCl}_{2}$ and $\mathrm{HIO}_{3} .{ }^{59}$ Although $\mathrm{CuCl}_{2}$ can be replaced in the synthesis of $\mathrm{Gd}\left(\mathrm{IO}_{3}\right)_{3}\left(\mathrm{H}_{2} \mathrm{O}\right)$ by other $\mathrm{Cu}^{2+}$ salts (such as $\mathrm{Cu}\left(\mathrm{NO}_{3}\right)_{2}, \mathrm{Cu}\left(\mathrm{SO}_{4}\right)_{2}$ and $\mathrm{Cu}\left(\mathrm{CH}_{3} \mathrm{COO}\right)_{2}$ ), studies showed that a $\mathrm{Cu}^{2+}$ cation is necessary. ${ }^{59}$ The $\mathrm{Cu}^{2+}$ methodology was applied in attempts to synthesize 1, 2, and other rare-earth iodate homologues, but all were unsuccessful, which we attribute to the differences in ionic radii and electronic configurations of different $\mathrm{RE}^{3+}$ cations. The blue precipitates from these reactions are residual $\mathrm{Cu}^{2+}$ salts. In contrast to $\mathrm{Cu}^{2+}$, the excess tetrafluoroboric acid used for the synthesis of $\mathbf{2}$ is easily removed by washing with deionized water, and therefore does not contaminate the final solid products. The $\mathrm{La}\left(\mathrm{NO}_{3}\right)_{3} \cdot 6 \mathrm{H}_{2} \mathrm{O}$ used in the preparation of 3 can be replaced by other $\mathrm{La}^{3+}$ sources (e.g. $\mathrm{La}_{2} \mathrm{O}_{3}$ and $\left.\mathrm{La}_{2}\left(\mathrm{CO}_{3}\right)_{3}\right)$, but the yields are lower; the method reported in the Experimental Section affords the highest yield. The purities of the three crystalline products were confirmed by PXRD studies, the powder patterns matching the simulations (Fig. S1).

\section{Crystal structures}
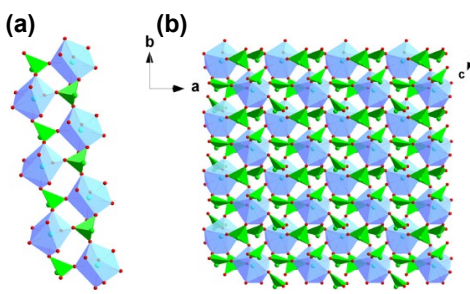

(c)

(d)

(e)

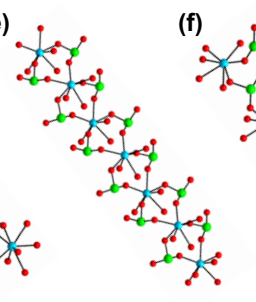

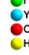
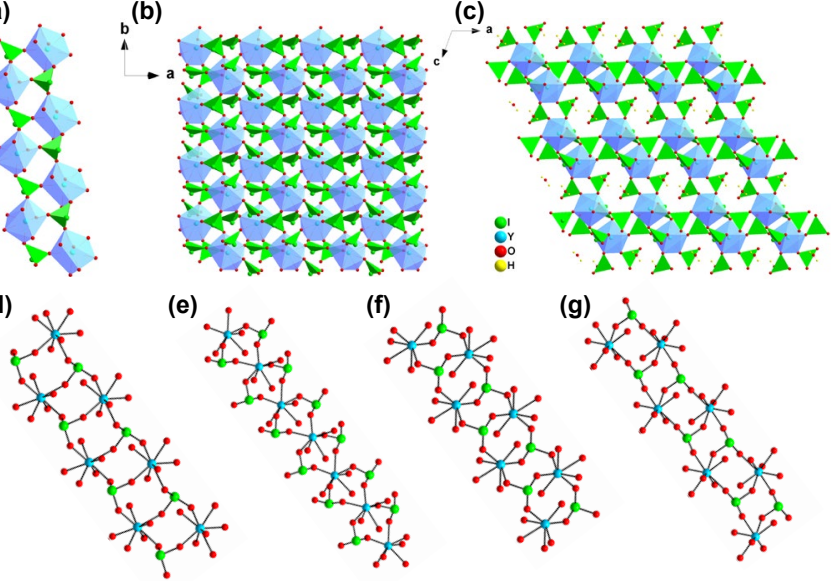

Fig. 1 (a) View of the 1D chain along the $b$-axis. (b) View of the layer structure in the $a b$ plane. (c) Perspective view of the 3D framework structure of 1 along the $b$-axis. Views of the $1 \mathrm{D}$ chains in (d) 1 , (e) $\alpha-Y\left(\mathrm{IO}_{3}\right)_{3}$, (f) $6-\mathrm{Y}\left(\mathrm{IO}_{3}\right)_{3}$ and $(\mathrm{g}) \mathrm{Y}\left(\mathrm{H}_{2} \mathrm{O}\right)_{2}\left(\mathrm{IO}_{3}\right)_{3}$.

$\mathbf{1}$ and $\mathbf{2}$ are isostructural, both crystallizing in the chiral monoclinic space group $P 2_{1}$ (No. 4), and so only the structure of 1 will be described in detail. The asymmetric unit cell of 1 contains one $\mathrm{Y}$, three $\mathrm{I}$, ten $\mathrm{O}$ and two $\mathrm{H}$ crystallographicallyindependent atoms. The $Y$ atom is coordinated with eight $O$ atoms, giving a $\mathrm{YO}_{8}$ unit with a distorted bicapped trigonalprismatic geometry, while the three crystallographically unique $\mathrm{I}$ atoms are all found in $\left[\mathrm{IO}_{3}\right]^{-}$trigonal-pyramidal anions. The iodate anions are formed from three-coordinated $\mathrm{I}^{5+}$ cation with a distortion opposite to the lone pair of $1^{5+}$. Thus, the asymmetric $\left[\mathrm{IO}_{3}\right]^{-}$units exhibit a pyramid geometry configuration and possess a local polarity. The bond lengths of $\mathrm{Y}-\mathrm{O}$ and $\mathrm{I}-\mathrm{O}$ are in the ranges $2.274(6)-2.482(6) \AA$ and $1.785(6)-1.826(5) \AA$, respectively, in good agreement with those reported in other $Y$-contained iodates. ${ }^{60}$ In the structure of $1, \mathrm{YO}_{8}$ polyhedra and $\left[\mathrm{IO}_{3}\right]^{-}$groups share their apical $\mathrm{O}$ atoms to build non-coplanar eight-membered rings (8-MRs) of $\left[\left(\mathrm{YO}_{6}\right)_{2}\left(\mathrm{IO}_{3}\right)_{2}\right]$; the 8 -MRs are linked, forming infinite chains along the $b$-axis (Fig. 1a). These 1D chains built pseudo-layers parallel to the $a b$ plane (Fig. $1 \mathrm{~b}$ ) by linking adjoining chains through $\left[1(1) \mathrm{O}_{3}\right]$ groups. The $2 \mathrm{D}$ layers are connected to the adjacent layers by corner-sharing $\left[\mathrm{I}\left(3 \mathrm{O}_{3}\right]\right.$ groups (as the layerlinkers), creating a 3D hierarchical framework structure (Fig. 1C). The $\mathrm{H}_{2} \mathrm{O}$ molecules locate in the channels, resulting in the formation of hydrogen bonds with the distances of $\mathrm{H} \cdots \mathrm{O}$ ranging from 2.190-2.580 $\AA$ (Table S3). BVS calculations on $\mathrm{Y}(1)$, $\mathrm{I}(1), \mathrm{I}(2)$, and $\mathrm{I}(3)$ in 1 give the values 3.16, 5.03, 5.18, and 5.11, respectively, which are in good agreement with formal oxidation states of +3 for $Y$ and +5 for $I$.

We also compared the structure of 1 with those of $\alpha$-/ 8 $\mathrm{Y}\left(\mathrm{IO}_{3}\right)_{3}{ }^{57}$ and $\mathrm{Y}\left(\mathrm{H}_{2} \mathrm{O}\right)_{2}\left(\mathrm{IO}_{3}\right)_{3},{ }^{61}$ because they have similar chemical components. Although $\alpha-Y\left(\mathrm{IO}_{3}\right)_{3}$ and $6-\mathrm{Y}\left(\mathrm{IO}_{3}\right)_{3}$ have the same chemical formulas, their structures are quite distinct, the former being assembled into a 3D framework, while the latter exhibits a $2 \mathrm{D}$ sheet structure. In sharp contrast to $\mathbf{1}$ and $\alpha$-/ 6 $\mathrm{Y}\left(\mathrm{IO}_{3}\right)_{3}$ with the aforementioned multi-dimensional structures, $\mathrm{Y}\left(\mathrm{H}_{2} \mathrm{O}\right)_{2}\left(\mathrm{IO}_{3}\right)_{3}$ features a $1 \mathrm{D}$ chain structure with two $\mathrm{H}_{2} \mathrm{O}$ molecules each coordinated to one $\mathrm{Y}$ atom. Such hydrated rare- 
(a)

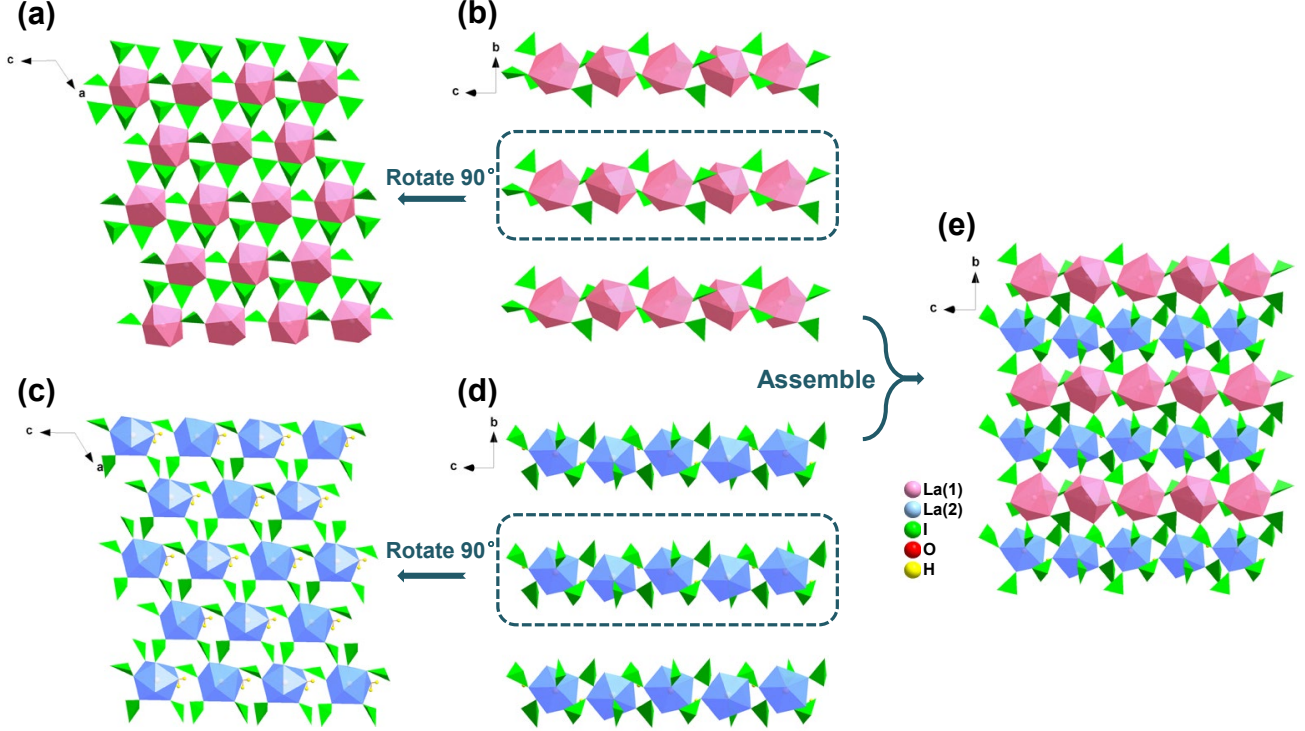

Fig. 2 Crystal structure of 3. The $2 \mathrm{D}$ layer (layer A) composed of $\mathrm{La}(1) \mathrm{O}_{9}$ polyhedra and $1 \mathrm{O}_{3}$ groups viewed down the $b$-axis (a) and viewed down the $a$-axis (b). The $2 \mathrm{D}$ layer (layer $\mathrm{B}$ ) composed of $\mathrm{La}(2)_{8}\left(\mathrm{H}_{2} \mathrm{O}\right)$ polyhedra and $\mathrm{IO}_{3}$ groups viewed down the $b$-axis (c) and viewed down the $a$-axis (d). (e) The 3D framework structure from the alternating stacking of layer $\mathrm{A}$ and layer $\mathrm{B}$.

earth iodates are more likely to show a low-dimensional structure if more $\mathrm{H}_{2} \mathrm{O}$ molecules are bonded to the rare-earth metals. In contrast, the coordinated $\mathrm{O}$ atom from $\left[\mathrm{IO}_{3}\right]^{-}$groups can link one rare-earth atom with another via a $\mathrm{IO}_{3}$ bridge, favoring a more highly connected framework. While the four compounds are all constructed from zigzag $\left[\mathrm{Y}_{2} \mathrm{I}_{2} \mathrm{O}_{4}\right]_{\infty}$ chains, they all have distinctive configurations and connectivity. As shown in Fig. 1, the chains in $\mathbf{1}$ are constructed from only one type of $\left[\mathrm{Y}_{2} \mathrm{I}_{2} \mathrm{O}_{4}\right]$ 8-MRs via sharing the $\mathrm{Y}-\mathrm{O}-\mathrm{I}$ edges, while in $\alpha$ $\mathrm{Y}\left(\mathrm{IO}_{3}\right)_{3}$ the $\left[\mathrm{Y}_{2} \mathrm{I}_{2} \mathrm{O}_{4}\right]$ 8-MRs are linked by corner-sharing common $\mathrm{Y}$ atoms. In the case of $8-\mathrm{Y}\left(\mathrm{IO}_{3}\right)_{3}$ and $\mathrm{Y}\left(\mathrm{H}_{2} \mathrm{O}\right)_{2}\left(\mathrm{IO}_{3}\right)_{3}$, the 1D chains are constructed from two distinct $\left[\mathrm{Y}_{2} \mathrm{I}_{2} \mathrm{O}_{4}\right]$ 8-MRs that are connected in an alternating fashion via edge-sharing.

Compound 3 crystallizes in the polar monoclinic space group $P c$ (No. 7) as a 3D framework structure composed of asymmetric $\mathrm{LaO}_{9} / \mathrm{LaO}_{8}\left(\mathrm{H}_{2} \mathrm{O}\right)$ and trigonal pyramidal $\left[\mathrm{IO}_{3}\right]^{-}$groups. The crystallographically independent components within the asymmetric unit are two $\mathrm{La}$, six $\mathrm{I}$, nineteen $\mathrm{O}$ and two $\mathrm{H}$ atoms. The BVS calculations show the mean valences for La and I in $\mathbf{3}$ are 3.19 and 4.97, respectively. Two unique La atoms are in two different nine-coordination environments: the nine ligating $O$ atoms all arise from $\left[\mathrm{IO}_{3}\right]^{-}$groups in $\mathrm{La}(1)$, while eight $\mathrm{O}$ atoms from $\left[\mathrm{IO}_{3}\right]^{-}$anions and one from $\mathrm{H}_{2} \mathrm{O}$ molecule are coordinated to $\mathrm{La}(2)$. Since $\mathrm{La}(1)$ is connected to more $\left[\mathrm{IO}_{3}\right]^{-}$groups, the average $\mathrm{La}(1)-\mathrm{O}$ bond length, lying in the range 2.512(6)2.703(6) $\AA$ (ave. $2.569 \AA$ ), is slightly longer than that of $\mathrm{La}(2)-\mathrm{O}$ (range 2.478(6)-2.685(7) $\AA$, ave. $2.553 \AA$ ) for steric reasons. Each formally $1^{5+}$ cation has three "normal" $1-O$ bonds (range: 1.794(6)-1.841(7) Å) and one much longer I-O bond (2.555(6) A I(1), 2.472(6) ̊ I(2)). Considering the normal bond lengths only, the BVS calculations give values of 4.91 for I(1) and 5.02 for I(2), so the $\left[1(1) \mathrm{O}_{3}\right]$ and $\left[1(2) \mathrm{O}_{3}\right]$ polyhedra can be described as trigonal pyramids with three normal $\mathrm{I}-\mathrm{O}$ bonds and one longer and weaker $1-O$ interaction. Each $\mathrm{La}(1)$ atom is connected to three I(1), two I(2) and two I(5) atoms via the 0 bridges and is linked to the adjacent $\mathrm{La}(1)$ atoms through these $\left[\mathrm{IO}_{3}\right]^{-}$bridges, leading to an infinite layer (layer A) in the $a c$-plane (as shown in Fig. $2 a$ and $2 b$ ). Similarly, each $\operatorname{La}(2)$ atom connects to other adjacent $\mathrm{La}(2)$ atoms, forming a different type of infinite layer (layer $\mathrm{B}$ ) in the ac-plane through two $\left[\mathrm{I}(3) \mathrm{O}_{3}\right]$, two $\left[\mathrm{I}(4) \mathrm{O}_{3}\right]$ and two $\left[\mathrm{I}(6) \mathrm{O}_{3}\right.$ ] linkages (Fig. $2 \mathrm{c}$ and $2 \mathrm{~d}$ ). These two types of layers (layer $A$ and layer $B$ ) are then further linked via common $\left[\mathrm{I}(2) \mathrm{O}_{3}\right],\left[\mathrm{I}(3) \mathrm{O}_{3}\right],\left[\mathrm{I}(4) \mathrm{O}_{3}\right]$ and $\left[\mathrm{I}(5) \mathrm{O}_{3}\right]$ groups in an ABAB stacking manner, building a 3D double-layered framework (Fig. 2e). The water molecules form hydrogen bonds with iodate groups (O$\mathrm{H} \cdots \mathrm{O}$ and $\mathrm{O}-\mathrm{H} \cdots \mathrm{I})$ with distance range of $1.880-2.910 \AA$ providing further stability for the double-layered structure (Table S3).

\section{Thermal properties}

Thermogravimetric (TGA) analyses were carried out to evaluate the thermal behavior of the crystals 1-3. The TGA plots (Fig. S2) show that $\mathbf{1}$ and $\mathbf{2}$ are thermally stable up to around $150{ }^{\circ} \mathrm{C}$ under a flow of nitrogen gas while 3 is stable up to $310^{\circ} \mathrm{C}$. Above $150{ }^{\circ} \mathrm{C}$, crystals 1-2 display two distinct weight-loss stages. The initial weight losses of $2.8 \%$ for 1 and $2.5 \%$ for $\mathbf{2}$ between 150 ${ }^{\circ} \mathrm{C}$ and $250{ }^{\circ} \mathrm{C}$ are consistent with the loss of one $\mathrm{H}_{2} \mathrm{O}$ molecule

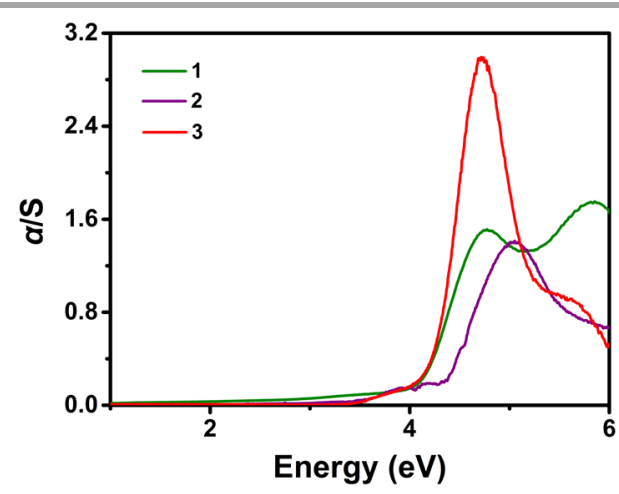

Fig. 3 Experimental band gaps of 1, 2 and $\mathbf{3}$. 
(a)

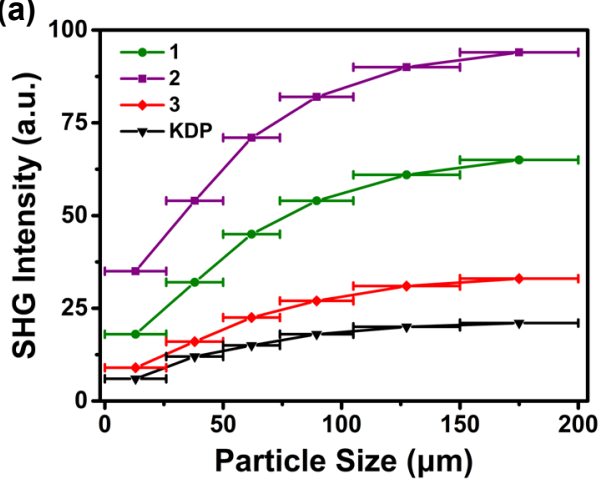

(b)

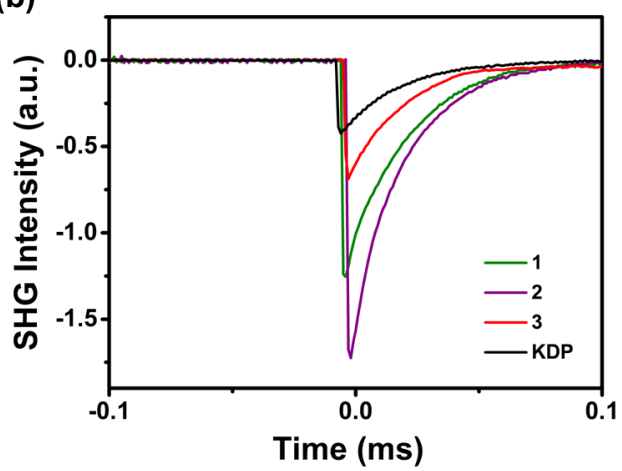

Fig. 4 (a) Phase-matching behavior of 1, 2, and 3. (b) Oscilloscope traces of the SHG signals of 1, 2, 3, and KDP in the particle size range 105-150 $\mu \mathrm{m}$.

per formula unit; for 3 , the initial weight loss of $2.2 \%$ is not observed until a temperature range of $360{ }^{\circ} \mathrm{C}$ to $450{ }^{\circ} \mathrm{C}$ is achieved. The significant differences in initial-weight-loss temperatures between $\mathbf{1} \mathbf{2}$ and $\mathbf{3}$ can be attributed to the different $\mathrm{H}_{2} \mathrm{O}$ locations in the three compounds; the $\mathrm{H}_{2} \mathrm{O}$ molecules in $\mathbf{1}$ and $\mathbf{2}$ are located in the channels and are not bound to any atoms in the structural framework, while those in $\mathbf{3}$ are coordinated to the La atoms. The second weight losses of $76.1 \%, 69.4 \%$ and $68.7 \%$ for $\mathbf{1}, \mathbf{2}$ and $\mathbf{3}$ occur in the temperature range $540-900{ }^{\circ} \mathrm{C}$, and correspond to the gradual release of $\mathrm{I}_{2}$ and $\mathrm{O}_{2}$ from decomposition of the $\mathrm{IO}_{3}$ units.

\section{Infrared spectra}

The IR spectra of crystalline 1-3 (Fig. S3) exhibit wide transparency ranges $\left(3250-970 \mathrm{~cm}^{-1}(3.0-11.3 \mu \mathrm{m})\right.$ for $\mathbf{1}$, $3080-980 \mathrm{~cm}^{-1}(3.2-10.4 \mu \mathrm{m})$ for 2, 3086-912 $\mathrm{cm}^{-1}(3.2-11.0$ $\mu \mathrm{m})$ for 3 ), which covers most of two key atmospheric transparency windows (bands II and III of 3-5 and 8-12 $\mu \mathrm{m}$, respectively). Absorption bands observed in the range 3080 to $3600 \mathrm{~cm}^{-1}$ are attributed to $\mathrm{O}-\mathrm{H}$ vibrations of the $\mathrm{H}_{2} \mathrm{O}$ molecules, and bands observed at $843,789,702$, and $580 \mathrm{~cm}^{-1}$ for $1,843,781$, and $700 \mathrm{~cm}^{-1}$ for 2 , and 766 and $729 \mathrm{~cm}^{-1}$ for 3 can be assigned to $\mathrm{I}-\mathrm{O}$ vibrations.

\section{UV-Vis-NIR diffuse reflectance spectra}

The UV-Vis-NIR diffuse reflectance spectra of 1-3 show that the three compounds have wide transparency regions extending from the UV to the NIR, consistent with their lack of color. The absorption edges of $\mathbf{1}, \mathbf{2}$ and $\mathbf{3}$ in the UV are approximately 301, 284 and $292 \mathrm{~nm}$, corresponding to optical band gaps of 4.12, 4.36 and $4.24 \mathrm{eV}$, respectively (Fig. 3 and S4). The band gaps of 1-3 are significantly higher than those of commercially available IR NLO crystals (e.g. AgGaS 2.75 eV, ${ }^{9} \mathrm{AgGaSe}_{2} 1.82 \mathrm{eV},{ }^{10} \mathrm{ZnGeP}_{2}$ $\left.2.25 \mathrm{eV}^{11}\right)$, and also superior to those of outstanding NLO iodate materials (e.g. $\alpha / 6-\mathrm{AgI}_{3} \mathrm{O}_{8} 3.78$ and $3.59 \mathrm{eV},{ }^{27} \mathrm{BiOlO}_{3} 3.3 \mathrm{eV},{ }^{28}$ $\mathrm{Bi}_{2}\left(\mathrm{IO}_{4}\right)\left(\mathrm{IO}_{3}\right)_{3} 3.3 \mathrm{eV}, 62$ and $\left.\mathrm{Bi}\left(\mathrm{IO}_{3}\right) \mathrm{F}_{2} 3.97 \mathrm{eV}\right) .^{63}$ The differences in band gaps mainly derive from the differences in electropositivity. In comparison with the iodates mentioned above, the larger band gaps of 1-3 arise from the more electropositive character of the rare-earth cations. Among existent rare-earth iodates, the band gaps of 1-3 are comparable to the largest reported thus far (e.g., $\mathrm{La}_{3}\left(\mathrm{IO}_{3}\right)_{8}(\mathrm{OH})$ $(4.34 \mathrm{eV}),{ }^{33} \mathrm{NaLa}\left(\mathrm{IO}_{3}\right)_{4}(4.16 \mathrm{eV}),{ }^{34}$ and $\left.\mathrm{NaSm}\left(\mathrm{IO}_{3}\right)_{4}(4.01 \mathrm{eV})^{34}\right)$ and, indeed, to the best of our knowledge, 2 possesses the largest band gap among SHG-active rare-earth-based iodates.

\section{Laser damage threshold measurements}

The excellent band gaps of the three title compounds suggest that 1-3 may possess high LDTs. As a result, the LDT values of polycrystalline samples of 1-3 and $\mathrm{AgGaS}_{2}$ were measured under the same experimental conditions. Crystals 1-3 have very large LDTs $\left(110.5,89.4\right.$, and $\left.92.1 \mathrm{MW} / \mathrm{cm}^{2}\right)$, which are 53, 43 and 44 times that of $\mathrm{AgGaS}_{2}\left(2.1 \mathrm{MW} / \mathrm{cm}^{2}\right)$, respectively. The
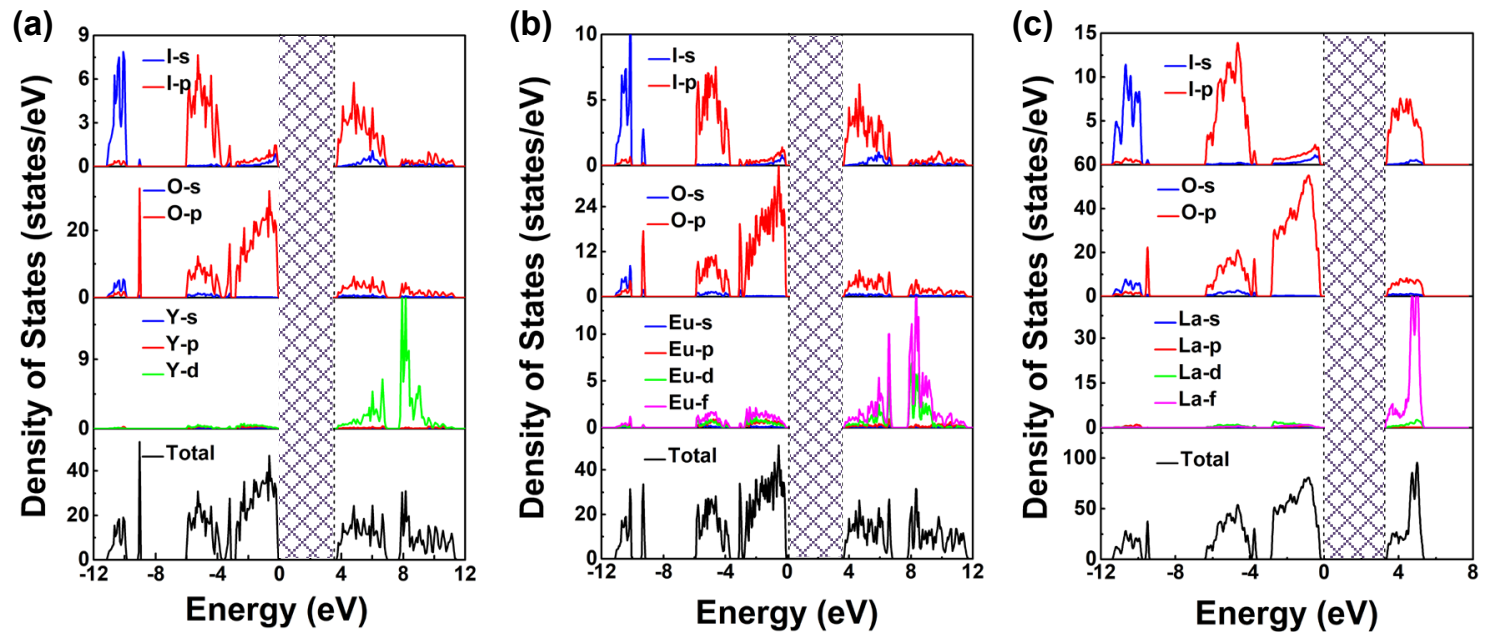

Fig. 5 Total density of states (DOS) and partial density of states (PDOS) of (a) 1, (b) 2, and (c) 3. Fermi level (dashed) located at zero. 
(a)

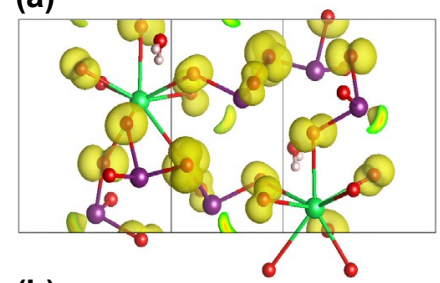

(b)

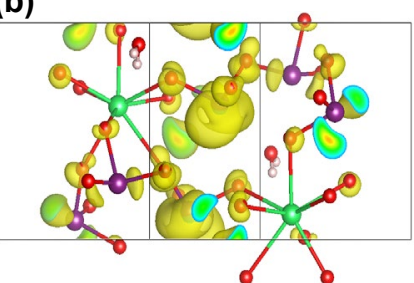

(c)

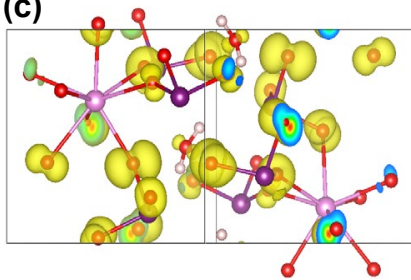

(d)

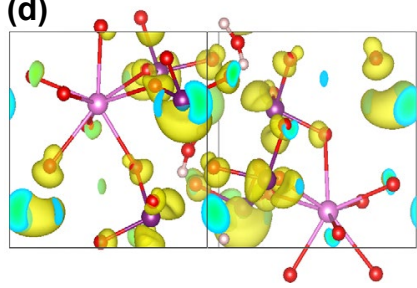

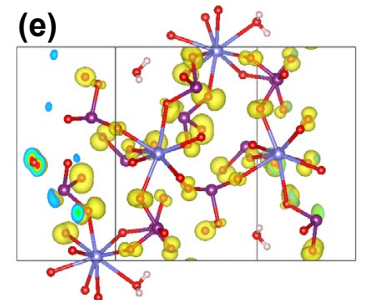

(f)

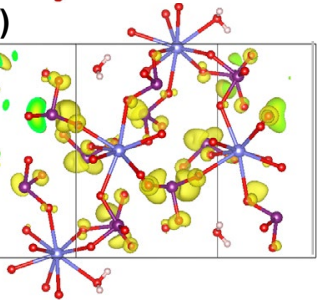

Fig. 6 Electron density maps at the Fermi level for $\mathbf{1}$ ((a) VBM, (b) CBM), $\mathbf{2}$ ((c) VBM, (d) CBM), and $\mathbf{3}$ ((e) VBM, (f) CBM). The isosurface value is set to 0.0032 eV $\AA^{-3}$. Purple, l; red, O; white, $\mathrm{H}$; green, $\mathrm{Y}$; pink, Eu; blue, La.

title compounds 1-3 therefore exhibit both larger band gaps and higher LDTs than AgGaS 2 , further confirming their promise in high-energy laser application.

\section{Second-harmonic generation properties}

Because 1-3 crystallize in chiral and NCS space groups, powder SHG measurements using a $1064 \mathrm{~nm}$ radiation were conducted, using polycrystalline KDP as reference. The SHG studies revealed that 1-3 are type I phase-matchable under $1064 \mathrm{~nm}$ radiation (Fig. 4a), and that these compounds exhibit large SHG signals in the particle size range of $105-150 \mu \mathrm{m}$. The SHG signals of $\mathbf{1}, \mathbf{2}$ and $\mathbf{3}$ are approximately 3.0, 4.5 and 1.5 times that of $\mathrm{KDP}$, respectively (Fig. 4b). According to anionic group theory, ${ }^{64}$ the observed strong SHG responses for the three compounds can be mainly attributed to the polarization from the lone-paircontaining asymmetric $\left[\mathrm{IO}_{3}\right]^{-}$groups rather than the rare-earth oxide polyhedra. For $\mathbf{1}$ and $\mathbf{2}$, the dipole moments for the $\left[\mathrm{IO}_{3}\right]^{-}$ groups constructively add along the $b$-axis in each unit cell (Fig. S5), leading to large net polarizations that are responsible for the observed strong SHG responses. However, the arrangement pattern of the $\left[\mathrm{IO}_{3}\right]^{-}$groups in the framework of $\mathbf{3}$ results in the partial cancellation of net dipole moments, which are unfavorable for the generation of a large SHG effect. The SHG responses of the title compounds, especially 1-2, are superior to those of most rare-earth-containing iodate NLO crystalline materials..$^{33,34,41,43,66}$

\section{Theoretical studies}

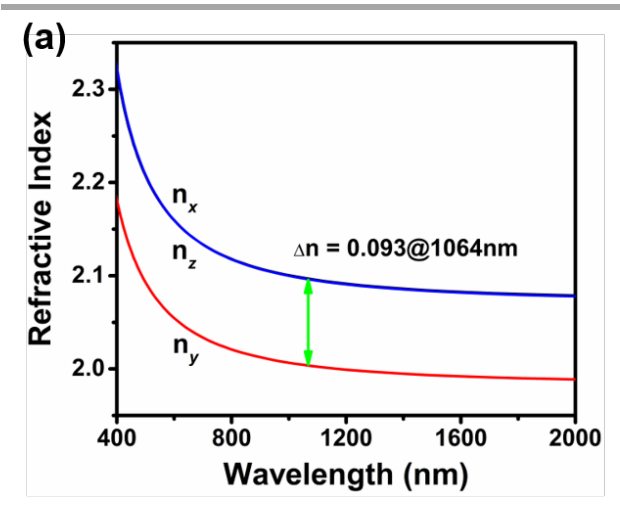

Fig. 7 Calculated refractive indexes of $\mathbf{1}$ (a), $\mathbf{2}$ (b) and $\mathbf{3}$ (c).
To enhance understanding of the bonding interactions in the title compounds, band structure and DOS calculations based on density functional theory (DFT) were performed. The calculated band-structure plots of 1-3 (Fig. S6) show wide band gaps of $3.88 \mathrm{eV}$ (1), $3.81 \mathrm{eV}$ (2) and $3.67 \mathrm{eV}$ (3), indicating semiconductor character. [Note that the calculated band gaps are smaller than the experimental values because of the limitations of the exchange and correlation function of GGA$\mathrm{PBE}$. The valence band maximum (VBM) and the conduction band minimum (CBM) of 1-2 are both located at point $B$, indicating that $\mathbf{1}$ and $\mathbf{2}$ are direct band gap compounds, while $\mathbf{3}$ has an indirect band gap with VBM and CBM located at point $A$ and point $G$, respectively. The total and partial density of states (DOS) diagrams of 1-3 are shown in Fig. 5. In all cases, the electronic states of the $\mathrm{I}$ atoms overlap with those of the $\mathrm{O}$ atoms across the whole region, consistent with strong interactions in the $\mathrm{I}-\mathrm{O}$ bonds. The $\mathrm{O}$ atoms also interact with the rare-earth cations, primarily via the overlap of the $0-2 p$ states with the Y-4d (1), Eu-5d and Eu-4f (2), and La-5d and La$4 \mathrm{f}$ states (3). The overlaps between the electronic states around the Fermi level indicate the origin of the optical properties. The VBM is mainly derived from $1-5 p$ and $0-2 p$ states, while the CBM is mostly composed of $1-5 p$ and $0-2 p$ states together with $Y-4 d$ states of 1, Eu-5d and Eu-4f states of 2, and La-5d and La-4f states of $\mathbf{3}$. The band gaps of 1-3 are therefore mainly determined by the $\left[\mathrm{IO}_{3}\right]^{-}$groups and the rare-earth oxide polyhedra. As shown in the electronic density maps at the VBM (b)

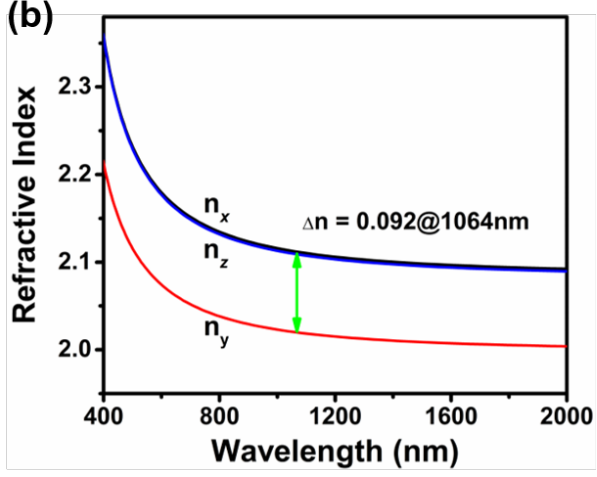

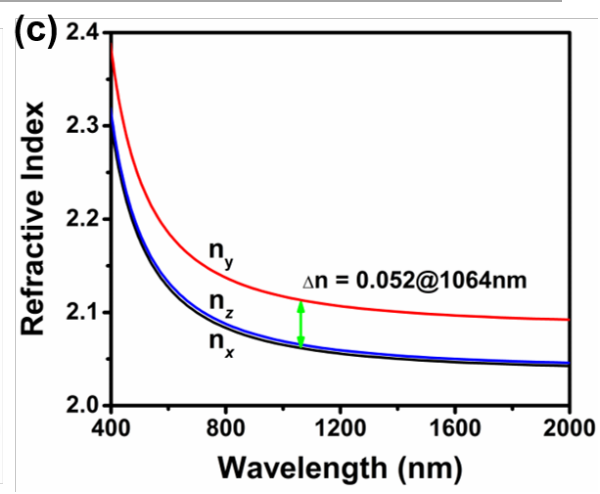


and CBM (Fig. 6), there is asymmetric electron density around the $I$ atoms in the form of a hemisphere-like shape, consistent with the presence of lone-pair. The I and $\mathrm{O}$ atoms form strong covalent bonds consistent with hybridization of the I-5p and O$2 p$ orbitals, resulting in strong electron delocalization around the Fermi level; this is the main source of the NLO effects such as SHG and birefringence.

The SHG susceptibilities of 1-3 were also calculated to afford further insight into the second-order NLO properties of the title compounds (Fig. S7). The three independent SHG tensors $d_{21}$, $d_{22}$, and $d_{23}$ at the laser wavelength of $1064 \mathrm{~nm}$ were calculated to be $2.26 \times 10^{-9}, 1.76 \times 10^{-9}$, and $2.84 \times 10^{-9}$ esu for 1 , and 1.09 $\times 10^{-8}, 4.42 \times 10^{-9}$, and $2.73 \times 10^{-9}$ esu for 2 , respectively. The six independent SHG tensors $d_{11}, d_{12}, d_{13}, d_{15}, d_{32}$, and $d_{33}$ for 3 at $1064 \mathrm{~nm}$ were calculated to be $2.30 \times 10^{-9}, 1.25 \times 10^{-9}, 5.22 \times$ $10^{-9}, 1.37 \times 10^{-9}, 3.05 \times 10^{-9}$, and $1.23 \times 10^{-9}$ esu, respectively. The mean SHG tensors of the three compounds were estimated to be $2.1,5.5$ and 2.2 times that of KDP, confirming the strong SHG effects of 1-3. The refractive indexes of the three compounds were also calculated (Fig. 7). The birefringence values are in the range $0.090-0.138$ for $1,0.088-0.138$ for 2 and $0.050-0.080$ for 3 , over the wavelength range 400 to $2000 \mathrm{~nm}$, and are $0.093,0.092$ and 0.052 at $1064 \mathrm{~nm}$ for $1-3$, respectively. These indexes are large enough to ensure 1-3 achieving phase matching in the IR region.

\section{Conclusions}

Three new hydrous rare-earth iodates, $\mathrm{Y}\left(\mathrm{IO}_{3}\right)_{3} \cdot \mathrm{H}_{2} \mathrm{O}$ (1), $\mathrm{Eu}\left(\mathrm{IO}_{3}\right)_{3} \cdot \mathrm{H}_{2} \mathrm{O}(2)$ and $\mathrm{La}_{2}\left(\mathrm{IO}_{3}\right)_{6}\left(\mathrm{H}_{2} \mathrm{O}\right)(3)$, have been synthesized under hydrothermal conditions. $\mathbf{1}$ and $\mathbf{2}$ are isostructural and feature 3D hierarchical frameworks that are composed of corner-sharing $\mathrm{REO}_{8}$ polyhedra and $\left[\mathrm{IO}_{3}\right]^{-}$pyramids with $1 \mathrm{D}$ chains of 8-MRs along the $b$-axis. 3 features a 3D framework constructed from two distinct kinds of layers stacking alternately. Powder SHG measurements reveal that 1-3 exhibit relatively strong SHG responses of ca. $3.0 \times, 4.5 \times$, and $1.5 \times \mathrm{KDP}$ under $1064 \mathrm{~nm}$ laser irradiation with type I phase-matching behavior. They additionally possess large band gaps of 4.12, 4.36 and $4.24 \mathrm{eV}$, wide transparency windows into the infrared region, and high LDTs $\left(53 \times, 43 \times\right.$, and $\left.44 \times \mathrm{AgGaS}_{2}\right)$. This study demonstrates that the three rare-earth iodates with high LDTs and strong SHG responses are potential candidate second-order NLO materials, and that the introduction of rare-earth cations with moderate electropositivity into iodates may achieve a balance between SHG efficiency and optical band gaps that is conductive to the construction of high-performance secondorder NLO materials for practical applications.

\section{Conflicts of interest}

There are no conflicts to declare.

\section{Acknowledgements}

This research was financially supported by the National Natural Science Foundation of China (no. 51432006), the Ministry of Education of China for the Changjiang Innovation Research Team (no. IRT13R24), the Ministry of Education and the State Administration of Foreign Experts Affairs for the 111 Project (no. B13025), and the Innovation Program of Shanghai Municipal Education Commission. M. G. H. and C. Z. thank the Australian Research Council for support (DP170100411).

\section{References}

1 K. M. Ok, E. O. Chi and P. S. Halasyamani, Bulk characterization methods for non-centrosymmetric materials: second harmonic generation, piezoelectricity, pyroelectricity, and ferroelectricity, Chem. Soc. Rev., 2006, 35, 710-717.

2 R. Dorn, D. Baums, P. Kersten and R. Regener, Inorganic lanthanide compounds with complex anions, Adv. Mater., 2002, 4, 464-473.

3 B. J. Eggleton, B. Luther-Davies and K. Richardson, Chalcogenide photonics, Nat. Photonics, 2011, 5, 141-148.

4 V. G. Dmitriev, G. G. Gurzadyan and D. N. Nikogosyan, Handbook of Nonlinear Optical Crystals, Springer, Berlin, 1999.

5 C. T. Chen, Y. C. Wu, A. D. Jiang, B. C. Wu, G. M. You, R. K. Li and S. J. Lin, New nonlinear-optical crystal: $\mathrm{LiB}_{3} \mathrm{O}_{5}$, J. Opt. Soc. Am. B, 1989, 5, 616-621.

6 Y. C. Wu, T. Sasaki, S. Nakai, A. Yokotani, H. G. Tang and C. T. Chen, $\mathrm{CsB}_{3} \mathrm{O}_{5}$ : a new nonlinear optical crystal, Appl. Phys. Lett., 1993, 62, 2614-2615.

7 C. T. Chen, Y. B. Wang, B. C. Wu, K. C. Wu, W. L. Zeng and L. H. $\mathrm{Yu}$, Design and synthesis of an ultraviolet-transparent nonlinear optical crystal $\mathrm{Sr}_{2} \mathrm{Be}_{2} \mathrm{~B}_{2} \mathrm{O}_{7}$, Nature, 1995, 373, 322324.

8 M. E. Hagerman and K. R. Poeppelmeier, Review of the structure and processing-defect-property relationships of potassium titanyl phosphate: a strategy for novel thin-film photonic devices, Chem. Mater., 1995, 7, 602-621.

9 D. S. Chemla, P. J. Kupecek, D. S. Robertson and R. C. Smith, Silver thiogallate, a new material with potential for infrared devices, Opt. Commun., 1971, 3, 29-31.

10 G. Boyd, H. Kasper, J. McFee and F. Storz, Linear and nonlinear optical properties of some ternary selenides, IEEE J. Quantum Electron., 1972, 8, 900-908.

11 G. D. Boyd, E. Buehler and F. G. Storz, Linear and nonlinear optical properties of $\mathrm{ZnGeP}_{2}$ and CdSe, Appl. Phys. Lett., 1971, 18, 301-304.

12 Z. Z. Luo, C. S. Lin, W. L. Zhang, H. Zhang, Z. Z. He and W. D. Cheng, $\mathrm{Ba}_{8} \mathrm{Sn}_{4} \mathrm{~S}_{15}$ : a strong second harmonic generation sulfide with zero dimensional crystal structure, Chem. Mater., 2014, 26, 1093-1099.

13 C. D. Morris, I. Chung, S. Park, C. M. Harrison, D. J. Clark, J. I. Jang and M. G. Kanatzidis, Molecular germanium selenophosphate salts: phase-change properties and strong second harmonic generation, J. Am. Chem. Soc., 2012, 134, 20733-20744.

14 P. S. Halasyamani and K. R. Poeppelmeier, Noncentrosymmetric oxides, Chem. Mater., 1998, 10, 27532769.

15 P. Becker, Borate materials in nonlinear optics, Adv. Mater. 1998, 10, 979-992.

16 C. Wu, G. Yang, M. G. Humphrey and C. Zhang, Recent advances in ultraviolet and deep-ultraviolet second-order nonlinear optical crystals, Coord. Chem. Rev., 2018, 375, 459488. 
17 Y. G. Shen, S. G. Zhao, J. H. Luo, The role of cations in secondorder nonlinear optical materials based on $\pi$-conjugated $\left[\mathrm{BO}_{3}\right]^{3-}$ groups, Coord. Chem. Rev., 2018, 366, 1-28.

18 C. L. Hu and J. G. Mao, Recent advances on second-order NLO materials based on metal iodates, Coord. Chem. Rev., 2015, 288, 1-17.

19 Y. G. Chen, N. Yang, X. N. Yao, C. B. Li, Y. Guo and X. M. Zhang, Synergetic influence of alkali-metal and lone-pair cations on frameworks of tellurites, Inorg. Chem., 2018, 57, 5406-5412.

20 C. Wu, L. Lin, X. X. Jiang, Z. S. Lin, Z. P. Huang, M. G. Humphrey, P. S. Halasyamani and C. Zhang, $\mathrm{K}_{5}\left(\mathrm{~W}_{3} \mathrm{O}_{9} \mathrm{~F}_{4}\right)\left(\mathrm{IO}_{3}\right)$ : an efficient mid-infrared nonlinear optical compound with high laser damage threshold, Chem. Mater., 2019, 31, 10100-10108.

21 K. M. Ok, P. S. Halasyamani, D. Casanova, M. Llunell, P. Alemany and S. Alvarez, Distortions in octahedrally coordinated $\mathrm{d}^{0}$ transition metal oxides: a continuous symmetry measures approach, Chem. Mater., 2006, 18, 31763183.

22 J. J. Zhang, Z. H. Zhang, W. G. Zhang, Q. X. Zheng, Y. X. Sun, C. Q. Zhang and X. T. Tao, Polymorphism of $\mathrm{BaTeMo}_{2} \mathrm{O}_{9}$ : a new polar polymorph and the phase transformation, Chem. Mater., 2011, 23, 3752-3761.

$23 \mathrm{H}$. W. Yu, M. L. Nisbet and K. R. Poeppelmeier, Assisting the effective design of polar iodates with early transition metal oxide fluoride anions, J. Am. Chem. Soc., 2018, 140, 88688876.

24 H. M. Liu, X. X. Jiang, X. X. Wang, L. Yang, Z. S. Lin, Z. G. Hu, X G. Meng, X. G. Chen and J. G. Qin, Influence of a-site cations on germanium iodates as mid-ir nonlinear optical materials: $\mathrm{A}_{2} \mathrm{Ge}\left(\mathrm{IO}_{3}\right)_{6}(\mathrm{~A}=\mathrm{Li}, \mathrm{K}, \mathrm{Rb}$ and $\mathrm{Cs})$ and $\mathrm{BaGe}\left(\mathrm{IO}_{3}\right)_{6} \cdot \mathrm{H}_{2} \mathrm{O}$, J. Mater Chem. C, 2018, 6, 4698-4705.

25 W. S. Otaguro, E. Wiener-Avnear and S. P. S. Porto, Determination of the second-harmonic-generation coefficient and the linear electro-optic coefficient in $\mathrm{LilO}_{3}$ through oblique raman phonon measurements, Appl. Phys. Lett., 1971, 18, 499-501.

26 D. Phanon and I. Gautier-Luneau, Promising material for infrared nonlinear optics: $\mathrm{Nal}_{3} \mathrm{O}_{8}$ salt containing an octaoxotriiodate(v) anion formed from condensation of $\left[\mathrm{IO}_{3}\right]^{-}$ ions, Angew. Chem. Int. Ed., 2007, 46, 8488-8491.

27 X. Xu, C. L. Hu, B. X. Li, B. P. Yang and J. G. Mao, $\alpha-\mathrm{Agl}_{3} \mathrm{O}_{8}$ and $\beta-\mathrm{Agl}_{3} \mathrm{O}_{8}$ with large shg responses: polymerization of $1 \mathrm{O}_{3}$ groups into the $\mathrm{I}_{3} \mathrm{O}_{8}$ polyiodate anion, Chem. Mater., 2014, 26, 3219-3230.

28 S. D. Nguyen, J. Yeon, S. H. Kim and P. S. Halasyamani, $\mathrm{BiO}\left(\mathrm{IO}_{3}\right)$ : a new polar iodate that exhibits an aurivillius-type $\left(\mathrm{Bi}_{2} \mathrm{O}_{2}\right)^{2+}$ layer and a large SHG response, J. Am. Chem. Soc., 2011, 133, 12422-12425.

29 Q. Wu, H. M. Liu, F. C. Jiang, L. Kang, L. Yang, Z. S. Lin, Z. G. Hu, X. G. Chen, X. G. Meng and J. G. Qin, $\mathrm{RbIO}_{3}$ and $\mathrm{RbIO}_{2} \mathrm{~F}_{2}$ : two promising nonlinear optical materials in mid-IR region and influence of partially replacing oxygen with fluorine for improving laser damage threshold, Chem. Mater., 2016, 28, $1413-1418$

30 M. Zhang, C. Hu, T. Abudouwufu, Z. H. Yang and S. L. Pan, Functional materials design via structural regulation originated from ions introduction: a study case in cesium iodate system, Chem. Mater., 2018, 30, 1136-1145.

31 Q. Wu, X. G. Meng, C. Zhong, X. G. Chen and J. G. Qin, $\mathrm{Rb}_{2} \mathrm{CdBr}_{2} \mathrm{I}_{2}$ : a new IR nonlinear optical material with a large laser damage threshold, J. Am. Chem. Soc., 2014, 136, 56835686.

32 Y. Huang, X. G. Meng, P. F. Gong, L. Yang, Z. S. Lin, X. G. Chen and J. G. Qin, $\mathrm{A}_{2} \mathrm{Bil}_{5} \mathrm{O}_{15}\left(\mathrm{~A}=\mathrm{K}^{+}\right.$or $\left.\mathrm{Rb}^{+}\right)$: two new promising nonlinear optical materials containing $\left[\mathrm{I}_{3} \mathrm{O}_{9}\right]^{3-}$ bridging anionic groups, J. Mater. Chem. C, 2014, 2, 4057-4062.

33 F. F. Mao, C. L. Hu, B. X. Li and J. G. Mao, Acentric $\mathrm{La}_{3}\left(\mathrm{IO}_{3}\right)_{8}(\mathrm{OH})$ and $\mathrm{La}\left(\mathrm{IO}_{3}\right)_{2}\left(\mathrm{NO}_{3}\right)$ : partial substitution of iodate anions in $\mathrm{la}\left(\mathrm{io}_{3}\right)_{3}$ by hydroxide or nitrate anion, Inorg. Chem., 2017, 56, 14357-14365.

34 S. J. Oh, H. G. Kim, H. Jo, T. G. Lim, J. S. Yoo and K. M. Ok Photoconversion mechanisms and the origin of secondharmonic generation in metal iodates with wide transparency, $\mathrm{NaLn}\left(\mathrm{IO}_{3}\right)_{4}(\mathrm{Ln}=\mathrm{La}, \mathrm{Ce}, \mathrm{Sm}$, and $\mathrm{Eu})$ and $\mathrm{NaLa}\left(\mathrm{IO}_{3}\right)_{4}: \mathrm{Ln}^{3+}(\mathrm{Ln}=\mathrm{Sm}$ and $\mathrm{Eu})$, Inorg. Chem., 2017, 56, 6973-6981.

35 F. Kong, Y. X. Ma and J. G. Mao, Lanthanide inorganic solids based on main group borates and oxyanions of lone pair cations, Chin. J. Chem., 2018, 36, 63-72.

36 T. Eaton, J. Lin, J. N. Cross, J. T. Stritzinger and T. E. AlbrechtSchmitt, $\mathrm{Th}\left(\mathrm{VO}_{3}\right)_{2}\left(\mathrm{SeO}_{3}\right)$ and $\mathrm{Ln}\left(\mathrm{VO}_{3}\right)_{2}\left(\mathrm{IO}_{3}\right)(\mathrm{Ln}=\mathrm{Ce}, \mathrm{Pr}, \mathrm{Nd}, \mathrm{Sm}$, and $\mathrm{Eu}$ ): unusual cases of aliovalent substitution, Chem. Commun., 2014, 50, 3668-3670.

37 T. C. Shehee, R. E. Sykora, K. M. Ok, P. S. Halasyamani and T. E. Albrecht-Schmitt, Hydrothermal preparation, structures, and nlo properties of the rare earth molybdenyl iodates, $\mathrm{RE}\left(\mathrm{MoO}_{2}\right)\left(\mathrm{IO}_{3}\right)_{4}(\mathrm{OH})[\mathrm{RE}=\mathrm{Nd}, \mathrm{Sm}, \mathrm{Eu}]$, Inorg. Chem., 2003, 42, 457-462.

$38 \mathrm{M}$. S. Wickleder, Inorganic lanthanide compounds with complex anions, Chem. Rev., 2002, 102, 2011-2088.

39 J. Chen, C. L. Hu, F. F. Mao, B. P. Yang, X. H. Zhang and J. G. Mao, $\mathrm{REI}_{5} \mathrm{O}_{14}(\mathrm{RE}=\mathrm{Y}$ and $\mathrm{Gd})$ : promising $\mathrm{SHG}$ materials featuringthe semicircle-shaped $\mathrm{I}_{5} \mathrm{O}_{14^{3-}}$ polyiodate anion. Angew. Chem. Int. Ed. 2019, 58, 11666-11669.

40 Y. X. Wang, T. Duan, Z. H. Weng, J. Ling, X. M. Yin, L. H. Chen D. P. Sheng, J. Diwu, Z. F. Chai, N. Liu and S. Wang, Inorganic lanthanide compounds with complex anions, Inorg. Chem., 2017, 56, 13041-13050.

41 L. Xiao, Z. B. Cao, J. Y. Yao, Z. S. Lin and Z. G. Hu, A new cerium iodate infrared nonlinear optical material with a large secondharmonic generation response, J. Mater. Chem. C, 2017, 5, 2130-2134.

42 T. Abudouwufu, M. Zhang, S. C. Cheng, Z. H. Yang and S. L. Pan, $\mathrm{Ce}\left(\mathrm{IO}_{3}\right)_{2} \mathrm{~F}_{2} \cdot \mathrm{H}_{2} \mathrm{O}$ : the first rare-earth-metal iodate fluoride with large second harmonic generation response, Chem. Eur. J., 2019, 25, 1221-1226.

43 K. M. Ok and P. S. Halasyamani, New metal iodates: syntheses, structures, and characterizations of noncentrosymmetric $\mathrm{La}\left(\mathrm{IO}_{3}\right)_{3}$ and $\mathrm{NaYl}_{4} \mathrm{O}_{12}$ and centrosymmetric $\beta-\mathrm{Cs}_{2} \mathrm{I}_{4} \mathrm{O}_{11}$ and $\mathrm{Rb}_{2} \mathrm{I}_{6} \mathrm{O}_{15}(\mathrm{OH})_{2} \cdot \mathrm{H}_{2} \mathrm{O}$, Inorg. Chem., 2005, 44, 9353-9359.

44 G. M. Sheldrick, SHELXL-97: Program for the Refinement of Crystal Structures, University of Göttingen, Germany, 1997.

45 G. M. Sheldrick, SHELXS-97: Program for the Solution of Crystal Structures, University of Göttingen, Germany, 1997.

46 N. E. Brese and M. O'Keeffe, Bond-valence parameters for solids, Acta Crystallogr. B, 1991, 47, 192-197.

47 A. L. Spek, Single-crystal structure validation with the program PLATON, J. Appl. Crystallogr., 2003, 36, 7-13.

48 G. Kortüm, Reflectance Spectroscopy, New York, 1969.

$49 \mathrm{~S}$. K. Kurtz and T. T. Perry, A powder technique for the evaluation of nonlinear optical materials, J. Appl. Phys., 1968, 39, 3798-3813.

50 M. J. Zhang, X. M. Jiang, L. J. Zhou and G. C. Guo, Two phases of $\mathrm{Ga}_{2} \mathrm{~S}_{3}$ : promising infrared second-order nonlinear optical materials with very high laser induced damage thresholds, $J$. Mater. Chem. C, 2013, 1, 4754-4760.

51 G. Kresse and J. Furthmuller, Efficient iterative schemes for $a b$ initio total-energy calculations using a plane-wave basis set, Phys. Rev. B, 1996, 54, 11169-11186.

52 J. P. Perdew, K. Burke and M. Ernzerhof, Generalized gradient approximation made simple, Phys. Rev. Lett., 1996, 77, 38653868.

53 P. E. Blochl, Projector augmented-wave method, Phys. Rev. B, 1994, 50, 17953-17979. 
54 G. Kresse and D. Joubert, From ultrasoft pseudopotentials to the projector augmented-wave method, Phys. Rev. B, 1999, 59, 1758-1775.

55 S. Sharma and C. Ambrosch-Draxl, Second-harmonic optical response from first principles, Phys. Scripta, 2004, T109, 128134.

56 C. G. Duan, J. Li, Z. Q. Gu and D. S. Wang, First-principles calculation of the second-harmonic-generation coefficients of borate crystals, Phys. Rev. B, 1999, 60, 9435-9443.

57 D. Phanon, A. Mosset and I. Gautier-Luneau, New iodate materials as potential laser matrices. preparation and characterisation of $\alpha-\mathrm{M}\left(\mathrm{IO}_{3}\right)_{3}\left(\mathrm{M}=\mathrm{Y}\right.$, Dy) and $6-\mathrm{M}\left(\mathrm{IO}_{3}\right)_{3}(\mathrm{M}=\mathrm{Y}$, $\mathrm{Ce}, \mathrm{Pr}, \mathrm{Nd}, \mathrm{Eu}, \mathrm{Gd}, \mathrm{Tb}, \mathrm{Dy}, \mathrm{Ho}, \mathrm{Er})$. Structural evolution as a function of the $\mathrm{Ln}^{3+}$ cationic radius, Solid State Sci., 2007, 9, 496-505.

58 W. X. Chai, J. Lin, L. Song, K. Y. Shu, L. S. Qin, H. S. Shi and J. Y. Guo, Two-dimensional topological structure and a series of corresponding plate-like $\mathrm{Ln}\left(\mathrm{IO}_{3}\right)_{3}\left(\mathrm{H}_{2} \mathrm{O}\right) \cdot \mathrm{H}_{2} \mathrm{O}(\mathrm{Ln}=\mathrm{Nd}, \mathrm{Eu}, \mathrm{Gd}$ Tb, Dy) nanomaterials: syntheses, structures and properties, Solid State Sci., 2010, 12, 2100-2105.

59 J. L. Lu, D. X. Zhang, L. Li and B. P. Liu, Hydrothermal synthesis of a chiral rare earth iodate $\left(\mathrm{Gd}\left(\mathrm{IO}_{3}\right)_{3} \cdot \mathrm{H}_{2} \mathrm{O}\right)$ showing the rare $(3,8)$ connected $\left(4^{3}\right)\left(4 \cdot 6^{2}\right)\left(4^{9} \cdot 6^{17} \cdot 8^{2}\right)$ topology, J. Coord. Chem., 2008, 61, 1406-1411.

60 A. L. Hector, S. J. Henderson, W. Levason and M. Webster Hydrothermal synthesis of rare earth iodates from the corresponding periodates: structures of $\mathrm{Sc}\left(\mathrm{IO}_{3}\right)_{3}$, $\mathrm{Y}\left(\mathrm{IO}_{3}\right)_{3} \cdot 2 \mathrm{H}_{2} \mathrm{O}, \mathrm{La}\left(\mathrm{IO}_{3}\right)_{3} \cdot 1 / 2 \mathrm{H}_{2} \mathrm{O}$ and $\mathrm{Lu}\left(\mathrm{IO}_{3}\right)_{3} \cdot 2 \mathrm{H}_{2} \mathrm{O}$, Z. Anorg. Allg. Chem., 2002, 628, 198-202.

61 A. L. Hector, W. Levason and M. Webster, Synthesis and properties of scandium, yttrium and lanthanum periodates. crystal structures of $\mathrm{Y}\left(\mathrm{H}_{2} \mathrm{O}\right)_{3}\left\{\mathrm{IO}_{4}(\mathrm{OH})_{2}\right\}$ and $\mathrm{Y}\left(\mathrm{H}_{2} \mathrm{O}\right)_{2}\left(\mathrm{IO}_{3}\right)_{3}$, Inorg. Chim. Acta, 2000, 298, 43-49.

62 Z. B. Cao, Y. C. Yue, J. Y. Yao, Z. S. Lin, R. He and Z. G. Hu, $\mathrm{Bi}_{2}\left(\mathrm{IO}_{4}\right)\left(\mathrm{IO}_{3}\right)_{3}$ : a new potential infrared nonlinear optical material containing $\left[1 \mathrm{IO}_{4}\right]^{3-}$ anion, Inorg. Chem., 2011, 50, 12818-12822.

63 F. F. Mao, C. L. Hu, X. Xu, D. Yan, B. P. Yang and J. G. Mao, $\mathrm{Bi}\left(\mathrm{IO}_{3}\right) \mathrm{F}_{2}$ : the first metal iodate fluoride with a very strong second harmonic generation effect, Angew. Chem. Int. Ed., 2017, 56, 2151-2155

64 C. T. Chen and G. Z. Liu, Recent advances in nonlinear optical and electro-optical materials, Annu. Rev. Mater. Sci., 1986, 16, 203-243.

65 T. Hu, L. Qin, F. Kong, Y. Zhou and J. G. Mao, $\operatorname{Ln}_{3} \mathrm{~Pb}_{3}\left(\mathrm{IO}_{3}\right)_{13}\left(\mu^{3}-\right.$ O) $(\mathrm{Ln}=\mathrm{La}-\mathrm{Nd})$ : new types of second-order nonlinear optical materials containing two types of lone pair cations, Inorg. Chem., 2009, 48, 2193-2199. 